\title{
Cardiac Autonomic Function in Adults Born Preterm
}

\author{
Risto Karvonen, $\mathrm{MD}^{1,2}$, Marika Sipola, MD, $\mathrm{PhD}^{1,2,3,4}$, Antti Kiviniemi, $\mathrm{PhD}^{5}$, Marjaana Tikanmäki, MD, $\mathrm{PhD}^{1,2,3}$, \\ Marjo-Riitta Järvelin, $\mathrm{MD}, \mathrm{PhD}^{3,6,7,8,9}$, Johan G. Eriksson, $\mathrm{MD}, \mathrm{PhD}^{10,11}$, Mikko Tulppo, $\mathrm{PhD}^{5}$, \\ Marja Vääräsmäki, $\mathrm{MD}, \mathrm{PhD}^{2,6}$, and Eero Kajantie, $\mathrm{MD}, \mathrm{PhD}^{1,2,12,13}$
}

Objective To evaluate cardiac autonomic function in adults born preterm.

Study design We studied the association between prematurity and cardiac autonomic function using heart rate variability measurements in 600 adults (mean age of 23.3 years) from a geographically based cohort in Northern Finland. There were 117 young adults born early preterm ( $<34$ weeks), 207 born late preterm (34-36 weeks), and 276 born at term ( $\geq 37$ weeks, controls). Autonomic function was analyzed by calculating time and frequency domain heart rate variability measurements using linear regression.

Results Compared with controls, the mean difference in root mean square of successive differences (indicating cardiac vagal activity) was $-12.0 \%(95 \% \mathrm{Cl}-22.2 \%,-0.5 \%$, adjusted for sex, age, source cohort, and season $P=.04)$ for the early preterm group and $-7.8 \%(-16.8 \%, 2.0 \%, P=.12)$ for the late preterm group. Mean differences with controls in low frequency power (indicating cardiac vagal activity, including some sympathetic- and baroreflexmediated effects) were $-13.6 \%(-26.7 \%, 1.8 \%, P=.08)$ for the early preterm group and $-16.4 \%(-27.0 \%,-4.3 \%$, $P=.01$ ) for the late preterm group. Mean differences in high frequency power (quantifying cardiac vagal modulation in respiratory frequency) were $-19.2 \%(-36.6 \%, 2.9 \%, P=.09)$ for the early preterm group and $-13.8 \%(-29.4 \%$, $5.3 \%, P=.15)$ for the late preterm group. Differences were attenuated when controlled for body mass index and physical activity.

Conclusions Our results suggest altered autonomic regulatory control in adults born preterm, including those born late preterm. Altered autonomic regulatory control may contribute to increased cardiovascular risk in adults born preterm. (J Pediatr 2019; $\mathbf{0}: 1-8)$.

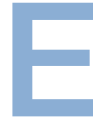

ach year, approximately 15 million infants worldwide are born preterm. ${ }^{1}$ Preterm birth is associated with an increased risk of cardiovascular disease in adult life. ${ }^{2-7}$ The risk factors for cardiovascular disease include increased blood pressure and blood pressure variability. ${ }^{8-10}$ The mechanisms that link preterm birth with elevated blood pressure remain unclear.

Altered cardiac autonomic function, manifested as depressed vagal and augmented sympathetic activity, is an important risk factor for cardiovascular morbidities. ${ }^{11-14}$ Heart rate (HR) variability (HRV) metrics are commonly used to assess cardiac autonomic function. ${ }^{11}$ A substantial proportion of the development of the autonomic nervous system (eg, myelination of the vagus nerve, baroreflex sensitivity, and HRV) occurs during the third trimester and is interrupted at preterm birth. ${ }^{15-17}$ Interrupted development of autonomic nervous system by preterm birth is likely to have consequences for autonomic control in later life. Altered cardiac autonomic function may be a potential candidate mechanism linking preterm birth with elevated blood pressure and cardiovascular risk factors in adulthood.

After birth, infants born preterm have altered autonomic control compared with those born at term. ${ }^{18}$ Follow-up studies of those born very preterm $(<32$ weeks) or with an extremely low birth weight $(<1000 \mathrm{~g})$ suggested that decreased cardiac autonomic control was present in childhood and young

\begin{tabular}{|ll}
\hline BMI & Body mass index \\
ESTER & Preterm Birth and Early-Life Programming of Adult Health and Disease \\
HF & High frequency \\
HFP & HF power \\
HR & Heart rate \\
HRV & HR variability \\
LF & Low frequency \\
LFP & LF power \\
rMSSD & Root mean square of successive differences \\
VLBW & Very low birth weight
\end{tabular}

From the ${ }^{1}$ Department of Chronic Disease Prevention, National Institute for Health and Welfare, Oulu and Helsinki, Finland; ${ }^{2}$ Research Unit for Pediatrics, Pediatric Neurology, Pediatric Surgery, Child Psychiatry, Dermatology, Clinical Genetics, Obstetrics and Gynecology, Otorhinolaryngology and Ophthalmology (PEDEGO), Medical Research Center Oulu, University of Oulu, Oulu, Finland; ${ }^{3}$ Institute of Health Sciences, Helsinki University Hospital and University of Helsinki, Helsinki, Finland; ${ }^{4}$ Department of Pediatrics and Adolescence, Oulu University Hospital, Oulu, Finland; ${ }^{5}$ Research Unit of Internal Medicine, Medical Research Center Oulu, Oulu University Hospital and University of Oulu, Oulu, Finland; ${ }^{6}$ Department of Children and Families, Oulu and Helsinki, Finland; ${ }^{7}$ Biocenter Oulu, Oulu, Finland; ${ }^{8}$ Unit of Primary Care Unit, Oulu, Finland; ${ }^{9}$ Department of Epidemiology and Biostatistics, Imperial College London, Medical Research Council Health Protection Agency Center for Environment and Health, School of Public Health, London, United Kingdom; ${ }^{10}$ Department of General Practice and Primary Health Care, Helsinki, Finland; ${ }^{11}$ Folkhälsan Research Center, Care, Helsinki, Finland; ${ }^{11}$ Folkhälsan Research
Helsinki, Finland; ${ }^{12}$ Hospital of Children and Adolescents, Helsinki University Hospital and University of Helsinki, Helsinki, Finland; and ${ }^{13}$ Department of Clinical and Molecular Medicine, Norwegian University of Science and Technology, Trondheim, Norway

The funding and conflict of interest statement is available at www.jpeds.com.

Portions of this study were presented at the Pediatric Academic Societies annual meeting, May 6-9, 2017, San Francisco, California.

0022-3476/\$ - see front matter. @ 2019 Elsevier Inc. All rights reserved. https://doi.org/10.1016/j.jpeds.2018.12.061 
adulthood. ${ }^{19-21}$ Research also indicated that adults who had an extremely low birth weight may experience premature decline in parasympathetic functioning during their $20 \mathrm{~s}$ and $30 \mathrm{~s} .{ }^{19}$ The findings of the aforementioned studies apply only to the smallest and most immature of infants. However, the majority of preterm births are moderate (32-33 weeks) or late (3436 weeks). Although many risk factors for cardiometabolic disease found in very preterm infants are also found in moderate and late preterm infants, whether these include altered cardiac autonomic function is not known. ${ }^{4,10}$ We hypothesized that preterm birth, throughout its entire range, is associated with decreased cardiac vagal control in young adults. We also hypothesized that higher blood pressure in adults born preterm may be linked to altered autonomic control.

\section{Methods}

The participants were part of the Preterm Birth and EarlyLife Programming of Adult Health and Disease (ESTER) study, a geographically based study in Northern Finland in which preterm adults and randomly selected control participants were recruited through the Northern Finland Birth Cohort 1986 (born 1985-1986) or Finnish Medical Birth Register (born 1987-1989). ${ }^{4,10}$

The selection and inclusion criteria of the study population are presented in Figure 1. All the study participants were offered a HR monitor. After exclusions (Figure 1), 117 early preterm adults ( $<34$ weeks), 207 late preterm adults (34-36 full weeks), ${ }^{3}$ and 276 full term control adults with available and sufficient HR data were included in the analysis.

\section{Perinatal Data}

Perinatal data on the participants recruited though the Northern Finland Birth Cohort 1986 have been reported previously. ${ }^{22}$ Corresponding data on the subjects recruited through the Finnish Medical Birth Register were collected from the patients' records at birth hospitals and maternal welfare clinics. ${ }^{23,24}$ Diagnoses of maternal gestational diabetes mellitus and gestational hypertension were confirmed according to the prevailing criteria at the time or by reviewing original hospital records. ${ }^{22-24}$ Small for gestational age was defined as a birth weight below -2 SDs of the mean according to sex and length of gestation. ${ }^{23,24}$ Very low birth weight (VLBW) was defined as a birth weight $<1500 \mathrm{~g}$.

\section{Measurements}

The subjects participated in clinical examinations at a mean age of 23.3 years (range 19.9-25.8 years). ${ }^{4}$ During the clinical examination, R-R intervals were recorded (RS800CX and WearLink WIND transmitter, Polar Electro Oy, Kempele, Finland) at a spontaneous breathing frequency in a seated position at the beginning of the examination day during a 10 to 15 -minute interview conducted by a study nurse.

To quantify cardiac autonomic function, the following measurements were obtained. In the time domain, the geo-

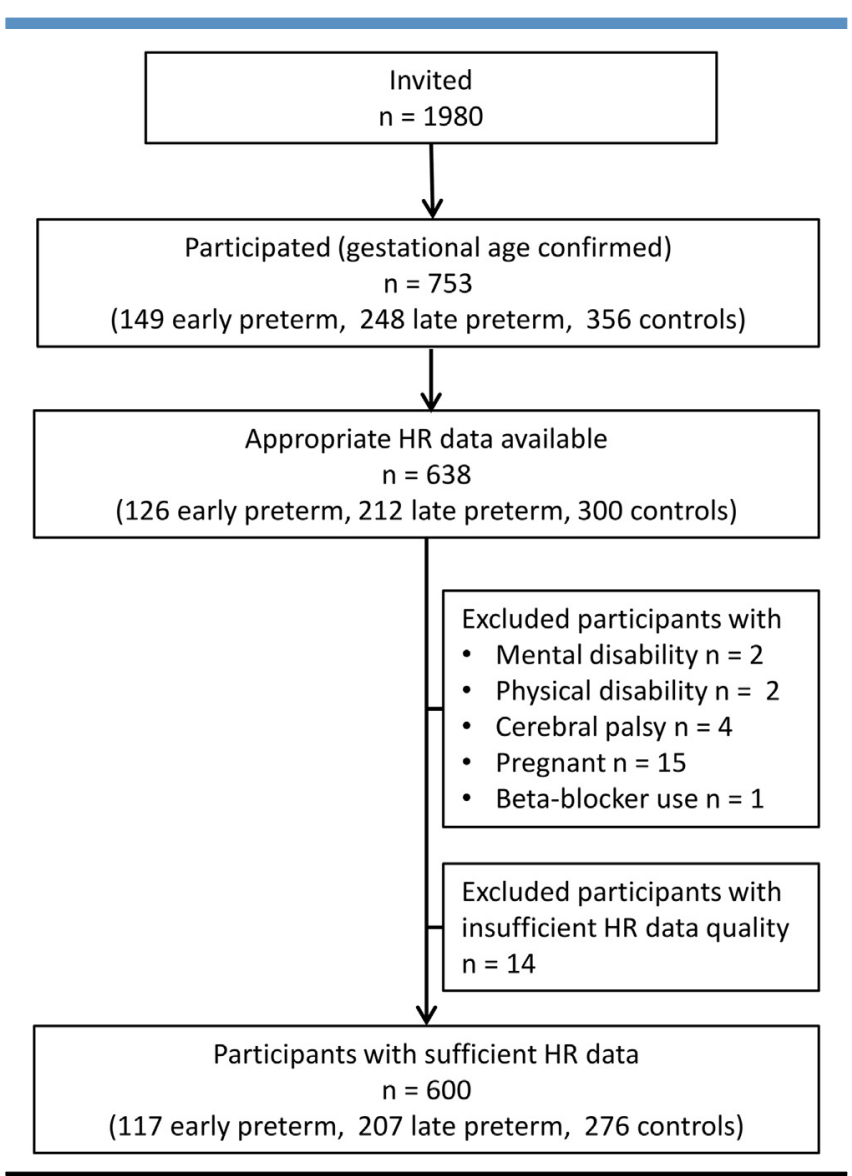

Figure 1. Flow chart of the study population.

metric mean HR and root mean square of successive differences (rMSSDs) were calculated. In the frequency domain, using a fast Fourier transform algorithm, low frequency (LF) power (LFP) $(0.04-0.15 \mathrm{~Hz})$, high frequency (HF) power (HFP) $(0.15-0.40 \mathrm{~Hz})$, and the ratio between LF and HF (LF/HF ratio) were determined.

Both rMSSD and HFP are considered metrics of cardiac vagal (parasympathetic) activity. ${ }^{25}$ Variation in the HF band quantifies the amplitude of variation in the spontaneous respiratory frequency $(0.20-0.25 \mathrm{~Hz})$ of humans. ${ }^{26}$ LFP includes some sympathetic- and baroreflex-mediated effects, in addition to cardiac vagal activity. ${ }^{25,27}$ The LF/HF ratio is considered a marker of sympathovagal balance, although there is some controversy as to its interpretation. ${ }^{28}$ We have included it to allow comparison with previous literature.

\section{Analysis of HRV}

In the analysis of HRV, 3-5 minutes of data were selected during a calm seated rest period at the beginning of the clinical examination. The most stationary 3- to 5-minute R-R interval data period with the lowest mean HR was selected based on a visual inspection. For 35, 44, and 521 participants, there were $3-4,4-5$, and at least 5 minutes of adequate stationary 
data selected for the analysis. Previous studies suggested that 2 minutes or more of HR data was adequate for spectral analysis and that as little as 1 minute of rMSSD data was adequate. ${ }^{25,29} \mathrm{R}-\mathrm{R}$ interval data were visually inspected for artifacts and ectopic beats and replaced with the local average. Sequences with more than 10 consecutive beats of ectopic beats or noise were deleted. R-R series with at least 3 minutes and a minimum of $90 \%$ of accepted R-R intervals were included in the analysis. The geometric mean HR, rMSSD, and frequency domain measurements of HRV by fast Fourier transform, LFP $(0.04-0.15 \mathrm{~Hz})$, HFP (0.15$0.40 \mathrm{~Hz}$ ), and LF/HF ratio were then calculated using an in-house script (Hearts 1.2 software, University of Oulu, Oulu, Finland). The measurements had a skewed distribution and, thus, were transformed into a natural logarithm (ln) prior to analysis but were transformed back and reported in untransformed form in Table I and II, Table III and IV(available at www.jpeds.com).

\section{Statistical Analyses}

Data were analyzed using SPSS Statistics for Windows v 24.0 software (IBM SPSS Statistics, IBM Corporation, Armonk, $\mathrm{NY}$ ). Descriptive statistics for the study groups were presented as categorical variables or mean values and standard deviations. Group differences were calculated by ANOVO, the Pearson $\chi^{2}$ test, or the Student $t$ test. Linear and logistic regressions were used to analyze differences in continuous and categorical variables. Because there was no statistically significant sex interaction in the regression analyses, we present the main results pooled for both sexes. However, as previous studies on the association between birth weight and autonomic control have shown sex differences, ${ }^{30}$ we also

Table I. Perinatal and neonatal characteristics of adults born early preterm, late preterm, and term (controls), in addition to current clinical and sociodemographic characteristics

\begin{tabular}{|c|c|c|c|c|c|c|c|c|c|c|c|c|c|c|}
\hline \multirow[b]{2}{*}{ Characteristics } & \multicolumn{5}{|c|}{ Early preterm $(n=117)$} & \multicolumn{5}{|c|}{ Late preterm $(n=207)$} & \multicolumn{4}{|c|}{ Controls $(n=276)$} \\
\hline & No. & $\%$ & Mean (SD) & Missing & $P$ value* & No. & $\%$ & Mean (SD) & Missing & $P$ value* & No. & $\%$ & Mean (SD) & Missing \\
\hline \multicolumn{15}{|l|}{ Perinatal and neonatal } \\
\hline Born from multiple pregnancies & 30 & 25.6 & & & $<.001$ & 27 & 13.4 & & & $<.001$ & & 0.7 & & \\
\hline Maternal hypertension ${ }^{\dagger}$ & 14 & 12.0 & & & .75 & 30 & 14.9 & & 5 & .23 & 30 & 10.9 & & 1 \\
\hline Maternal preeclampsia ${ }^{\ddagger}$ & 29 & 24.8 & & & $<.001$ & 23 & 11.4 & & 5 & .008 & 13 & 4.7 & & 1 \\
\hline Maternal gestational diabetes & 2 & 1.7 & & 19 & .85 & 6 & 3.2 & & 20 & .22 & 4 & 1.5 & & 7 \\
\hline $\begin{array}{l}\text { Maternal smoking during } \\
\text { pregnancy }\end{array}$ & 18 & 16.2 & & 6 & .89 & 42 & 20.6 & & 3 & .76 & 44 & 16.2 & & 5 \\
\hline Gestational age (wk) & & & $31.8(2.0)$ & & $<.001$ & & & $35.8(0.8)$ & & $<.001$ & & & $40.1(1.2)$ & \\
\hline Birth weight $(\mathrm{g})$ & & & $1780(493)$ & & $<.001$ & & & $2651(511)$ & & $<.001$ & & & 3607 (479) & \\
\hline Birth weight SD score & & & $-0.72(1.45)$ & & $<.001$ & & & $-0.68(1.3)$ & & $<.001$ & & & $0.04(1.0)$ & \\
\hline \multicolumn{15}{|l|}{ Current } \\
\hline Male sex & 58 & 49.6 & & & .94 & 101 & 48.8 & & & .79 & 138 & 50.0 & & \\
\hline Age $(y)$ & & & $23.1(1.3)$ & & .003 & & & $23.3(1.3)$ & & .04 & & & $23.5(1.1)$ & \\
\hline Parental education level & & & & 1 & .23 & & & & 4 & .79 & & & & 2 \\
\hline Basic or less or unknown & 11 & 9.4 & & & & 15 & 7.2 & & & & 15 & 5.4 & & \\
\hline Secondary & 68 & 58.1 & & & & 118 & 57.0 & & & & 169 & 61.2 & & \\
\hline Lower-level tertiary & 10 & 8.5 & & & & 28 & 13.5 & & & & 37 & 13.4 & & \\
\hline Upper-level tertiary & 27 & 23.1 & & & & 42 & 20.3 & & & & 53 & 19.2 & & \\
\hline $\begin{array}{l}\text { Self-reported physical activity } \\
\text { (MET h/wk) }\end{array}$ & & & $23.3(13.5)$ & & .08 & & & $25.3(14.7)$ & & .61 & & & $26.0(13.6)$ & \\
\hline Season of clinical examination & & & & & .18 & & & & & .06 & & & & \\
\hline Winter & 27 & 23.1 & & & & 48 & 23.2 & & & & 55 & 19.9 & & \\
\hline Spring & 33 & 28.2 & & & & 68 & 32.9 & & & & 70 & 25.4 & & \\
\hline Summer & 14 & 12.0 & & & & 28 & 13.5 & & & & 59 & 21.4 & & \\
\hline Fall & 43 & 36.8 & & & & 63 & 30.4 & & & & 92 & 33.3 & & \\
\hline Daily smoking & 50 & 24.2 & & & .14 & 33 & 28.2 & & & .01 & 59 & 21.4 & & \\
\hline BMI $\left(\mathrm{kg} / \mathrm{m}^{2}\right)$ & & & $24.2(4.5)$ & & .34 & & & $24.5(4.4)$ & & .05 & & & $23.8(3.9)$ & \\
\hline \multicolumn{15}{|l|}{ Height (cm) } \\
\hline Male & & & $178.9(6.9)$ & & .37 & & & $177.7(6.5)$ & & .87 & & & $177.9(6.9)$ & \\
\hline Female & & & $163.4(4.9)$ & & .31 & & & $164.6(5.8)$ & & .73 & & & $164.3(6.0)$ & \\
\hline Cohort of recruitment participation & 40 & 34.2 & & & $<.001$ & 99 & 47.8 & & & .01 & 164 & 59.4 & & \\
\hline Clinic systolic blood pressure $^{\S}$ & & & 119.2(13.2) & & .03 & & & $118.0(13.6)$ & & .10 & & & $116.0(12.5)$ & \\
\hline Clinic diastolic blood pressure ${ }^{\S}$ & & & $77.6(8.9)$ & & .007 & & & $76.6(8.3)$ & & .03 & & & $75.0(7.3)$ & \\
\hline$H R(b p m)^{9}$ & & & $71.8(1.2)$ & & .05 & & & $70.0(1.2)$ & & .46 & & & $69.2(1.2)$ & \\
\hline $\operatorname{rMSSD}(\mathrm{ms})^{\pi}$ & & & $49.6(1.8)$ & & .13 & & & $51.1(1.7)$ & & .17 & & & $54.7(1.8)$ & \\
\hline $\operatorname{LFP}\left(\mathrm{ms}^{2}\right)^{\pi}$ & & & $1563.9(2.1)$ & & .10 & & & $1507.5(2.1)$ & & .01 & & & $1788.2(2.1)$ & \\
\hline $\operatorname{HFP}\left(\mathrm{ms}^{2}\right)^{\pi}$ & & & $881.2(3.1)$ & & .21 & & & $912.8(2.8)$ & & .21 & & & $1032.9(3.1)$ & \\
\hline $\mathrm{LF} / \mathrm{HF}^{\text {I }}$ & & & $1.8(2.0)$ & & .75 & & & $1.7(1.9)$ & & .49 & & & $1.7(2.0)$ & \\
\hline
\end{tabular}

bpm, beats per minute; MET, metabolic equivalent.

${ }^{\star} P$ values refer to comparisons between preterm born subjects and controls using the Student $t$ test or Pearson $\chi^{2}$ test.

†Gestational or chronic hypertension.

†lncludes superimposed preeclampsia.

§Mean of 3 measurements.

IGeometric mean. 
Table II. Mean differences (95\% CIs) in HRV between early and late preterm adults compared with controls, with a post hoc analysis comparing all adults born preterm to controls

\begin{tabular}{|c|c|c|c|c|c|c|c|}
\hline \multirow[b]{2}{*}{ Measurements } & \multirow[b]{2}{*}{ Model } & \multicolumn{2}{|l|}{ Early preterm } & \multicolumn{2}{|l|}{ Late preterm } & \multicolumn{2}{|c|}{ Post hoc analysis of all preterms } \\
\hline & & Mean difference $(95 \% \mathrm{Cl})$ & $P$ value & Mean difference $(95 \% \mathrm{Cl})$ & $P$ value & Mean difference $(95 \% \mathrm{Cl})$ & $P$ value \\
\hline \multirow{3}{*}{ Mean HR (Control mean: 69.2 bpm) } & 1 & $3.4(-0.2$ to 7.0$)$ & .06 & 0.7 (-2.1 to 3.6$)$ & .63 & 1.6 (-1.0 to 4.3$)$ & .22 \\
\hline & 2 & $2.0(-1.8$ to 5.9$)$ & 31 & 0.3 (-2.7 to 3.3$)$ & .86 & 0.8 (-2.0 to 3.6$)$ & .57 \\
\hline & 3 & $0.8(-3.0$ to 4.7$)$ & .68 & $-0.5(-3.5$ to 2.6$)$ & .77 & -0.1 ( -2.9 to 2.8$)$ & .97 \\
\hline \multirow[t]{3}{*}{ rMSSD (Control mean: 54.7 ms) } & 1 & $-12.0(-22.2$ to -0.5$)$ & .04 & -7.8 ( -16.8 to 2.0$)$ & .12 & $-9.3(-17.3$ to -0.6$)$ & .04 \\
\hline & 2 & $-11.4(-22.5$ to 1.3$)$ & .08 & $-8.4(-17.7$ to 1.9$)$ & .11 & $-9.3(-17.9$ to 0.1$)$ & .05 \\
\hline & 3 & $-7.7(-19.4$ to 5.8$)$ & .25 & $-4.5(-14.4$ to 6.5$)$ & .40 & $-5.5(-14.6$ to 4.5$)$ & 27 \\
\hline \multirow[t]{3}{*}{ LFP (Control mean: $1788.2 \mathrm{~ms}^{2}$ ) } & 1 & $-13.6(-26.7$ to 1.8$)$ & .08 & $-16.4(-27.0$ to -4.3$)$ & .01 & $-15.5(-25.1$ to -4.5$)$ & .01 \\
\hline & 2 & -14.6 ( -28.5 to 2.0$)$ & .08 & $-16.5(-27.5$ to -3.7$)$ & .01 & $-15.9(-26.2$ to -4.1$)$ & .01 \\
\hline & 3 & $-9.8(-24.7$ to 8.2$)$ & .27 & $-12.9(-24.6$ to 0.8$)$ & .06 & $-11.9(-23.0$ to 0.8$)$ & .07 \\
\hline \multirow[t]{3}{*}{ HFP (Control mean: $1032.9 \mathrm{~ms}^{2}$ ) } & 1 & $-19.2(-36.6$ to 2.9$)$ & .09 & $-13.8(-29.4$ to 5.3$)$ & .15 & -15.7 ( -29.6 to 0.9$)$ & .06 \\
\hline & 2 & -19.4 ( -38.0 to 5.0$)$ & .11 & $-15.5(-31.5$ to 4.3$)$ & .12 & $-16.7(-31.4$ to 1.2$)$ & .07 \\
\hline & 3 & $-12.3(-32.9$ to 14.6$)$ & .34 & -7.8 (-25.6 to 14.2$)$ & .45 & $-9.3(-25.6$ to 10.7$)$ & .38 \\
\hline \multirow{3}{*}{ LF/HF (Control mean 1.7) } & 1 & $6.9(-7.8$ to 24.0$)$ & .37 & $-3.1(-14.2$ to 9.5$)$ & .61 & $0.3(-10.1$ to 12.0$)$ & .96 \\
\hline & 2 & $5.9(-9.8$ to 24.3$)$ & .48 & $-1.2(-13.1$ to 12.3$)$ & .85 & $1.0(-10.3$ to 13.7$)$ & 87 \\
\hline & 3 & $2.9(-12.6$ to 21.2$)$ & .73 & $-5.4(-17.1$ to 7.8$)$ & .40 & $-3.0(-14.0$ to 9.6$)$ & .63 \\
\hline
\end{tabular}

Model $1(n=600)$ : Age, sex, cohort of recruitment, and season of clinical examination.

Model $2(n=600)$ : Model 1 plus birth weight SD score, gestational diabetes mellitus, gestational hypertension, maternal preeclampsia, parental education, and parental smoking.

Model $3(n=583)$ : Model 2 plus smoking, BMI, height, and physical activity.

All group means are geometric means. Mean differences have been calculated from log transformed values, back-transformed, and expressed as percentage difference.

present the results separated by sex. Regression model 1 included age, sex, cohort of recruitment, and season of clinical examination as covariates. Season was included as covariate due to strong seasonality of physical activity and other lifestyle factors in Northern Finland. Model 2 described the controlled total effect of preterm birth (the effect not explained by confounders) on autonomic cardiac control in adulthood. In addition to model 1 covariates, model 2 included educational attainment of the higher educated parent (indicating socioeconomic status), birth weight SD scores, gestational diabetes mellitus, gestational hypertension, maternal preeclampsia, and maternal smoking as covariates. Model 3 reflected the direct effect of preterm birth (the effect not mediated through current characteristics) on autonomic cardiac control. It included, in addition to model 2 covariates, smoking habits, body mass index (BMI), height, and physical activity. As reported in earlier research, adults born preterm have a higher BMI, ${ }^{4}$ are less $\mathrm{fit}^{31}$ and engage less in leisure time physical activities. ${ }^{32}$ Therefore, BMI and physical activity were included as covariates.

\section{Results}

Perinatal, neonatal, sociodemographic, and clinical characteristics of the study groups are presented in Table I. Those born preterm had a lower birth weight SD score than controls. They were also more likely to be the result of multiple pregnancies, exposed to maternal preeclampsia more often, and had higher office blood pressure than full term controls. In terms of sociodemographic and clinical characteristics, the late preterm group had a higher BMI $(P=.05)$, and the early preterm group had lower selfreported physical activity $(P=.08)$, although neither difference reached statistical significance in this sample. In the late preterm group, mean LFP was lower $(P=.01)$, and there were more daily smokers $(P=.01)$ than in the control group. Otherwise, the sociodemographic and clinical background characteristics of the study groups were similar.

\section{Nonparticipant Analysis}

A detailed nonparticipant analysis of ESTER study participants has been published. ${ }^{4}$ We now report on the comparison of participants who were excluded based on inadequate HRV data quality to the participants included in this report. In this study, there were $12.7 \%$ subjects excluded because of inadequate HRV data quality from the analysis in the early preterm group, $14.5 \%$ in the late preterm group, and $19.3 \%$ in the control group $\left(\chi^{2}, P=.13\right)$. When comparing the background characteristics of the excluded with those included in analysis, among the early preterm group, the excluded infants had more mothers with gestational diabetes ( $11.7 \%$ vs $1.7 \%, P=.02$ ). Among the late preterm group, those excluded were younger (mean age 22.6 vs 23.3 years, $P=.001$ ), were less often part of the Northern Finland Birth Cohort $(25.7 \%$ vs $47.8 \%, P=.01)$, and their mothers had more gestational diabetes $(14.3 \%$ vs $2.9 \%, P=.003)$ when compared with the nonexcluded. In the control population, the excluded participants were older (23.8 vs 23.5 years, $P=.03)$, had lower birth weight SD scores $(-0.24$ vs 0.04 , $P=.04$ ), and higher diastolic blood pressures (77.5 vs 75.0 , $P=.03$ ). For other characteristics presented in Table I, there were no differences between the excluded and included participants within any group.

\section{Group Differences in Autonomic Function}

Geometric means and SDs in HRV measurements for the adults born early preterm, late preterm, and term (controls) 
are presented in Table I. We first compared these outcomes between the preterm groups and controls, adjusting for age, sex, cohort of recruitment, and season of clinical examination (Table II, model 1 and Figure 2; available at www.jpeds.com). The mean HR was slightly higher in the early preterm group, although these results were not statistically significant. Mean rMSSD, an indicator of cardiac vagal activity, was lower for those born early preterm and among all preterm young adults when compared with full term control participants. Furthermore, LFP, an additional indicator of cardiac vagal activity that also reflects sympathetic- and baroreflex-mediated effects, was lower for those born late preterm and among all preterm participants. The mean HFP, a measurement of cardiac vagal modulation in respiratory frequency, was also lower in all preterm groups, although the results were not statistically significant in any group (Table II). The LF/HF ratio, a measurement of sympathovagal balance, did not differ between the groups.

\section{Adjustment for Parental, Prenatal, Sociodemographic, and Clinical Characteristics}

When the regression analyses were further adjusted for birth weight SD score, gestational diabetes mellitus, gestational hypertension, maternal preeclampsia, parental education, and parental smoking in model 2 , the results showed little change (Table II). When adjusted further for daily smoking, BMI, height, and physical activity in model 3 , the results were no longer statistically significant (Table II). When the models were adjusted for sociodemographic and clinical characteristics, BMI and physical activity appeared to be the most important factors affecting between group differences in HRV measurements. For BMI, only statistical trends were noted, and each $1 \mathrm{~kg} / \mathrm{m}^{2}$ higher BMI predicted $1.0 \%$ lower rMSSD (95\% CI $-0.1 \%, 2.1 \%, P=.09)$, $0.9 \%$ lower LFP $(-2.4 \%, 6.0 \%, P=.2)$, and $2.1 \%$ lower HFP $(-0.1 \%, 4.3 \%, P=.06)$. Each metabolic equivalent hour/ week more physical activity was associated with $0.5 \%$ higher $\operatorname{rMSSD}(0.2 \%, 0.8 \%, P=.003), 0.6 \%$ higher LFP $(0.1 \%, 1.0 \%, P=.01)$, and $0.9 \%$ higher HFP $(0.3 \%, 1.6 \%$, $P=.006)$. To indicate additional proportion of variance explained by adding a variable in the full model, we calculated $\mathrm{R}^{2}$ change explained by the addition of BMI and physical activity, expressed in percentage points. Adding $\mathrm{BMI}$ in the model resulted in an $\mathrm{R}^{2}$ change of $0.4 \%$ for $\mathrm{HR}$, $0.5 \%$ for rMSSD, $0.2 \%$ for LFP, $0.6 \%$ for HFP, and $0.5 \%$ for LF/HF. For physical activity, corresponding numbers were $1.1 \%, 1.5 \%, 1.1 \%, 1.3 \%$, and $0.5 \%$. When adjusted for body fat percent instead of BMI in model 3, the results were similar (not shown).

\section{Associations between Autonomic Measurements and Blood Pressure}

Similar to the previously reported results in the ESTER study, ${ }^{4,10}$ the current early preterm group had higher mean systolic and diastolic blood pressure when adjusted for sex, age, cohort of recruitment, and season of clinical examina- tion (Table V). The late preterm group had higher mean systolic and diastolic blood pressure when adjusted for sex, age, cohort of recruitment, and season of clinical examination (Table V). Correlations between HRV measurements and blood pressure are shown in (Table VI; available at www.jpeds.com). When the difference in blood pressure between the preterm and term groups was further adjusted for rMSSD, HFP, and LFP, the differences attenuated slightly but remained statistically significant (Table V). An exception was in the difference in diastolic blood pressure in the late preterm group, which was $1.3 \mathrm{~mm} \mathrm{Hg}$ (95\% CI -0.2 to 2.7 ) higher when adjusted for sex, age, cohort of recruitment, season of clinical examination, and LFP.

\section{Sex Differences and VLBW}

Table III presents the results separately for women and men. The group differences in HRV measurements were nominally greater in men than women, especially for LFP, although no statistically significant sex interaction was found.

To allow comparison with previous literature, we present mean differences in HRV measurements for VLBW adults compared with controls (Table IV). No difference was statistically significant. However, the VLBW sample size was rather small $(\mathrm{n}=28)$.

\section{Discussion}

We hypothesized that preterm birth, throughout its whole range, is associated with decreased cardiac vagal control in young adults. The results revealed lower mean rMSSD, lower mean LFP, and to lesser extent lower mean HFP among young adults born preterm compared with those born at term, although the differences were not statistically significant in all comparisons. Although the CIs leave some uncertainty specifically as to the difference in cardiac vagal control,

Table V. Mean differences (95\% CIs) in systolic and diastolic office blood pressure between adults born early preterm and late preterm compared with controls, adjusted for HRV measurements

\begin{tabular}{|c|c|c|c|c|c|}
\hline \multirow[b]{2}{*}{ Measurements } & \multirow[b]{2}{*}{ Model } & \multicolumn{2}{|c|}{ Early preterm } & \multicolumn{2}{|c|}{ Late preterm } \\
\hline & & $\begin{array}{c}\text { Mean } \\
\text { difference } \\
\text { in } \mathbf{~ m m ~} \mathrm{Hg} \\
(95 \% \mathrm{Cl})\end{array}$ & $\begin{array}{c}P \\
\text { value }\end{array}$ & $\begin{array}{c}\text { Mean } \\
\text { difference } \\
\text { in } \mathrm{mm} \mathrm{Hg} \\
(95 \% \mathrm{Cl})\end{array}$ & $\begin{array}{c}P \\
\text { value }\end{array}$ \\
\hline \multirow{4}{*}{$\begin{array}{l}\text { Systolic blood } \\
\text { pressure }\end{array}$} & 1 & $3.5(1.2-5.8)$ & .003 & 2.2 (0.3 to 4.1$)$ & .021 \\
\hline & 2 & $3.1(0.9-5.5)$ & .006 & $2.0(0.2-3.9)$ & .034 \\
\hline & 3 & $3.3(1.0-5.5)$ & .005 & $2.1(0.2-4.0)$ & .032 \\
\hline & 4 & $3.2(1.0-5.5)$ & .005 & $1.9(0.0-3.8)$ & .048 \\
\hline \multirow{4}{*}{$\begin{array}{l}\text { Diastolic blood } \\
\text { pressure }\end{array}$} & 1 & $2.8(1.1-4.6)$ & .002 & $1.7(0.3-3.1)$ & .020 \\
\hline & 2 & $2.4(0.7-4.1)$ & .006 & $1.4(0.0-2.8)$ & .046 \\
\hline & 3 & $2.5(0.8-4.2)$ & .004 & $1.5(0.1-2.9)$ & .041 \\
\hline & 4 & $2.5(0.8-4.2)$ & .005 & $1.3(-0.2$ to 2.7$)$ & .080 \\
\hline
\end{tabular}

Model 1 ( $n=600)$ : Age, sex, cohort of recruitment, and season of clinical examination. Model $2(n=600)$ : Model 1 plus rMSSD.

Model $3(n=600)$ : Model 1 plus HFP.

Model $4(n=600)$ : Model 1 plus LFP. 
overall our results are consistent with altered autonomic regulatory control in adults born preterm, including those born late preterm. This association was attenuated after adjustment for BMI and physical activity, suggesting it was mediated at least in part by these factors.

We also hypothesized that higher blood pressure in adults born preterm may be linked to altered autonomic control. Consistent with this, the associations between preterm birth and blood pressure were somewhat attenuated when adjusted for HRV measurements. Therefore, altered cardiac autonomic control may be one mechanism by which cardiovascular risk is increased in adults born preterm. However, our results retain an amount of uncertainty and thus the hypothesis needs to be tested again.

Mechanisms that link preterm birth with adult cardiovascular risk factors, such as high blood pressure, remain unclear. A previous study reported that differences in stressinduced blood pressure were stronger than those in resting blood pressure among preterm born men. ${ }^{32}$ This finding provides support for altered autonomic regulatory control, including decreased cardiac vagal modulation, as underlying mechanisms linking preterm birth with adult cardiovascular risk factors. The findings of the present study are consistent with this idea. However, considerable proportion of variance in blood pressure variation remains unexplained by autonomic control measurements.

A number of previous studies provided evidence that altered sympathovagal balance or decreased vagal function were independent risk factors for all-cause mortality and a common underlying factor in all major risk factors for cardiovascular disease. ${ }^{11-14}$ Most previous studies on cardiac control in preterm born subjects focused on outcomes in infants and children. A study on 9-year-old children suggested an association between low birth weight and autonomic control irrespective of gestational age at birth. ${ }^{20}$ Relatively little is known on the outcomes of preterm birth to cardiac control in later life. It is possible that the alterations in cardiac autonomic regulatory control become more pronounced with increasing age and declining cardiovascular health. Impaired parasympathetic functioning and premature decline has indeed been shown in young adults born with an extremely low birth weight. ${ }^{19,21}$ A study of low birth weight adults suggested that the autonomic nervous system response varied by sex. ${ }^{33}$ In this study, there was no statistically significant sex interaction found in autonomic control.

The underlying biological mechanisms of the findings of the present study remain unclear. Altered autonomic control in infants born preterm has been previously reported. ${ }^{18}$ Whereas the sympathetic branch of the autonomic nervous system appears to develop most rapidly in the first trimester, vagal (parasympathetic) control becomes more dominant later in fetal development at 25-30 weeks of gestation and increases substantially during the third trimester of pregnancy. ${ }^{34,35}$ Previous studies showed that total myelinated vagus fibers in infants increased linearly with postconceptional age, leading to fewer total myelinated vagus fibers in preterm born infants than full term infants or adolescents. ${ }^{17}$
Therefore, these studies argue, interrupted gestation leads to lower cardiac vagal control. Our findings are consistent with this and suggest that altered autonomic regulatory control is present at least in young adult life.

Our study suggested that some differences in autonomic control may be greater among preterm born men than women (eg, LFP), although we found no statistically significant sex interactions overall. This is in contrast with association between preterm birth and adult office blood pressure that is stronger among women than men. ${ }^{30}$ Moreover, when low birth weight is used as an early life indicator, as summarized by a recent review, ${ }^{30}$ the associations with autonomic nervous system response to stress is stronger among women, whereas associations with hypothalamic-pituitaryadrenal axis and total peripheral resistance are stronger among men.

A previous study of the sympathetic nervous system response to psychosocial stress based on measurements of plasma adrenalin and noradrenalin concentrations among VLBW young adults found no evidence of higher responses in those born VLBW compared with controls. ${ }^{36}$ The same study found that the rise in noradrenalin concentrations after stress was lower in VLBW born women than in controls. ${ }^{36}$

Although we adjusted for a range of parental and prenatal confounders associated with preterm birth, these did not explain the associations between preterm birth and cardiac vagal control. This suggests that the associations we found are more likely to be associated with preterm birth per se rather than underlying causes of preterm birth. Previous studies from the same cohort showed that young adults born preterm had lower muscular fitness, lower perceived fitness, and higher body fat percentage than controls. ${ }^{4,31}$ Studies also reported that physical activity, body composition, and autonomic nervous system function were intrinsically associated. ${ }^{37-39}$ A recent study suggested that lifelong physical activity was positively associated with vagally mediated autonomic function, independently of traditional risk markers. ${ }^{40}$ We found that the differences in autonomic control measurements between the study groups were attenuated when adjusted for physical activity and BMI, suggesting that lower rates of physical activity and increased adiposity might partly mediate altered vagal control in preterm born adults.

We have previously discussed the limitations of the ESTER Preterm Birth Study. ${ }^{4}$ For the present study, usable HR data could not be obtained from a number of participants. Second, the recording of the R-R intervals was done during a study nurse visit that included a few questions on current health. Previous studies suggest that talking could impact to respiratory frequency and thus impact HRV measurements by increasing LFP and decreasing HFP. ${ }^{41-43}$ However, this would be expected to introduce bias only if the effects of talking on HRV would differ between the preterm and term groups. Such an outcome is unlikely, but cannot be excluded.

Third, in some participants, the available stationary HR data was shorter than 5 minutes. However, the inclusion of findings only from those participants with at least 5 minutes of data in the analysis had minor effect on the results. Fourth, 
the data quality of some R-R interval recordings was not sufficient for inclusion in the analysis. Therefore, the total sample size was limited, which might increase inaccuracy and lead to more conservative estimates.

We found that preterm born adults showed evidence of altered autonomic regulatory control compared with those born at term. This finding was also present for those born late preterm. The associations between preterm birth and higher blood pressure were somewhat attenuated when adjusted for HRV measurements, suggesting that altered autonomic regulatory control may contribute to the higher blood pressure. Consequently altered autonomic regulatory control may be one mechanism by which cardiovascular risk is increased in adults born preterm. Increased adiposity and reduced physical activity may partly mediate this association. From a clinical perspective, our results reinforce previous suggestions on the importance of health-enhancing physical activity and fitness among individuals born preterm.

Submitted for publication Apr 3, 2018; last revision received Dec 7, 2018; accepted Dec 31, 2018.

Reprint requests: Risto Karvonen, MD, Department of Chronic Disease Prevention, National Institute for Health and Welfare, PO Box 310, 90101 Oulu, Finland. E-mail: risto.karvonen@thl.fi

\section{References}

1. Blencowe H, Cousens S, Oestergaard MZ, Chou D, Moller A-B, Narwal R, et al. National, regional, and worldwide estimates of preterm birth rates in the year 2010 with time trends since 1990 for selected countries: a systematic analysis and implications. Lancet 2012;379:2162-72.

2. Parkinson JRC, Hyde MJ, Gale C, Santhakumaran S, Modi N. Preterm birth and the metabolic syndrome in adult life: a systematic review and meta-analysis. Pediatrics 2013;131:1240.

3. Sipola-Leppänen M, Vääräsmäki M, Tikanmäki M, Hovi P, Miettola S, Ruokonen A, et al. Cardiovascular risk factors in adolescents born preterm. Pediatrics 2014;134:e1072-81.

4. Sipola-Leppänen $M$, Vääräsmäki $M$, Tikanmäki $M$, Matinolli $H M$, Miettola S, Hovi P, et al. Cardiometabolic risk factors in young adults who were born preterm. Am J Epidemiol 2015;181:861-73.

5. Kajantie E, Hovi P. Is very preterm birth a risk factor for adult cardiometabolic disease? Semin Fetal Neonatal Med 2014;19:112-7.

6. Luu TM, Katz SL, Leeson P, Thébaud B, Nuyt A. Preterm birth: risk factor for early-onset chronic diseases. CMAJ 2016;188:736-46.

7. Raju TNK, Buist AS, Blaisdell CJ, Moxey-Mims M, Saigal S. Adults born preterm: a review of general health and system-specific outcomes. Acta Paediatr 2017;106:1409-37.

8. Hovi P, Vohr B, Ment LR, Doyle LW, McGarvey L, Morrison KM, et al. Blood pressure in young adults born at very low birth weight. Hypertension 2016;68:880-7.

9. Morrison KM, Ramsingh L, Gunn E, Streiner D, Van Lieshout R, Boyle M, et al. Cardiometabolic health in adults born premature with extremely low birth weight. Pediatrics 2016;138, in press.

10. Sipola-Leppänen M, Karvonen R, Tikanmäki M, Matinolli HM, Martikainen S, Pesonen AK, et al. Ambulatory blood pressure and its variability in adults born preterm. Hypertension 2015;65:615-21.

11. Tsuji H, Larson MG, Venditti FJ, Manders ES, Evans JC, FeldmanCL, et al. Impact of reduced heart rate variability on risk for cardiac events. The Framingham Heart Study. Circulation 1996;94:2850-5.

12. La Rovere MT, Bigger JT, Marcus FI, Mortara A, Schwartz PJ. Baroreflex sensitivity and heart-rate variability in prediction of total cardiac mortality after myocardial infarction. ATRAMI (autonomic tone and reflexes after myocardial infarction) investigators. Lancet 1998;351:478-84.
13. Thayer JF, Yamamoto SS, Brosschot JF. The relationship of autonomic imbalance, heart rate variability and cardiovascular disease risk factors. Int J Cardiol 2010;141:122-31.

14. Thayer JF, Lane RD. The role of vagal function in the risk for cardiovascular disease and mortality. Biol Psychol 2007;74:224-42.

15. Van Leeuwen P, Lange S, Bettermann H, Grönemeyer D, Hatzmann W. Fetal heart rate variability and complexity in the course of pregnancy. Early Hum Dev 1999;54:259-69.

16. Andriessen P, Oetomo SB, Peters C, Vermeulen B, Wijn PFF, Blanco CE. Baroreceptor reflex sensitivity in human neonates: the effect of postmenstrual age. J Physiol (Lond) 2005;568:333-41.

17. Sachis PN, Armstrong DL, Becker LE, Bryan AC. Myelination of the human vagus nerve from 24 weeks postconceptional age to adolescence. J Neuropathol Exp Neurol 1982;41:466-72.

18. Yiallourou SR, Witcombe NB, Sands SA, Walker AM, Horne RSC. The development of autonomic cardiovascular control is altered by preterm birth. Early Hum Dev 2013;89:145-52.

19. Mathewson KJ, Van Lieshout RJ, Saigal S, Boyle MH, Schmidt LA. Reduced respiratory sinus arrhythmia in adults born at extremely low birth weight: evidence of premature parasympathetic decline? Int J Psychophysiol 2014;93:198-203.

20. Rakow A, Katz-Salamon M, Ericson M, Edner A, Vanpée M. Decreased heart rate variability in children born with low birth weight. Pediatr Res 2013;74:339-43.

21. Mathewson KJ, Van Lieshout RJ, Saigal S, Morrison KM, Boyle MH, Schmidt LA. Autonomic functioning in young adults born at extremely low birth weight. Glob Pediatr Health 2015;2. 2333794X15589560.

22. Järvelin MR, Hartikainen-Sorri AL, Rantakallio P. Labour induction policy in hospitals of different levels of specialisation. Br J Obstet Gynaecol 1993;100:310-5.

23. Miettola S, Hartikainen AL, Vääräsmäki M, Bloigu A, Ruokonen A, Järvelin MR, et al. Offspring's blood pressure and metabolic phenotype after exposure to gestational hypertension in utero. Eur J Epidemiol 2013;28:87-98.

24. Vääräsmäki M, Pouta A, Elliot P, Tapanainen P, Sovio U, Ruokonen A, et al. Adolescent manifestations of metabolic syndrome among children born to women with gestational diabetes in a general-population birth cohort. Am J Epidemiol 2009;169:1209-15.

25. Heart rate variability: standards of measurement, physiological interpretation and clinical use. Task force of the European Society of Cardiology and the North American Society of Pacing and Electrophysiology. Circulation 1996;93:1043-65.

26. Eckberg DL. The human respiratory gate. J Physiol (Lond) 2003;548: 339-52.

27. Julien C. The enigma of Mayer waves: facts and models. Cardiovasc Res 2006;70:12-21.

28. Billmann GE. The LF/HF ratio does not accurately measure cardiac sympatho-vagal balance. Front Physiol 2013;4:26.

29. Esco MR, Flatt AA. Ultra-short-term heart rate variability indexes at rest and post-exercise in athletes: evaluating the agreement with accepted recommendations. J Sports Sci Med 2014;13:535-41.

30. Kajantie E, Räikkönen K. Early life predictors of the physiological stress response later in life. Neurosci Biobehav Rev 2010;35:23-32.

31. Tikanmäki $M$, Tammelin $T$, Sipola-Leppänen $M$, Kaseva $N$, Matinolli HM, Miettola S, et al. Physical fitness in young adults born preterm. Pediatrics 2016;137:1-10.

32. Tikanmäki $M$, Kaseva $N$, Tammelin $T$, Sipola-Leppänen $M$, Matinolli HM, Eriksson JG, et al. Leisure time physical activity in young adults born preterm. J Pediatr 2017;189:135-42.

33. Feldt K, Räikkönen K, Eriksson JG, Andersson S, Osmond C, Barker DJ, et al. Cardiovascular reactivity to psychological stressors in late adulthood is predicted by gestational age at birth. J Hum Hypertens 2007;21:401-10.

34. Fyfe KL, Yiallourou SR, Wong FY, Horne RSC. The development of cardiovascular and cerebral vascular control in preterm infants. Sleep Med Rev 2014;18:299-310.

35. Wakai RT. Assessment of fetal neurodevelopment via fetal magnetocardiography. Exp Neurol 2004;190(Suppl 1):65. 
36. Kaseva N, Pyhälä R, Wehkalampi K, Feldt K, Pesonen AK, Heinonen K, et al. Adrenalin, noradrenalin and heart rate responses to psychosocial stress in young adults born preterm at very low birthweight. Clin Endocrinol (Oxf) 2014;81:231-7.

37. Rossi M, Marti G, Ricordi L, Fornasari G, Finardi G, Fratino P, et al. Cardiac autonomic dysfunction in obese subjects. Clin Sci 1989;76:567-72.

38. Felber Dietrich D, Schindler C, Schwartz J, Barthélémy JC, Tschopp JM, Roche F, et al. Heart rate variability in an ageing population and its association with lifestyle and cardiovascular risk factors: results of the SAPALDIA study. Europace 2006;8:521-9.

39. Karason K, Mølgaard H, Wikstrand J, Sjöström L. Heart rate variability in obesity and the effect of weight loss. Am J Cardiol 1999;83:1242-7.
40. Kiviniemi AM, Perkiömäki N, Auvinen J, Herrala S, Hautala AJ, Ahola R, et al. Lifelong physical activity and cardiovascular autonomic function in midlife. Med Sci Sports Exerc 2016;48:1506-13.

41. Tininenko JR, Measelle JR, Ablow JC, High R. Respiratory control when measuring respiratory sinus arrhythmia during a talking task. Biol Psychol 2012;89:562-9.

42. Bernardi L, Wdowczyk-Szulc J, Valenti C, Castoldi S, Passino C, Spadacini G, et al. Effects of controlled breathing, mental activity and mental stress with or without verbalization on heart rate variability. J Am Coll Cardiol 2000;35:1462-9.

43. Beda A, Jandre FC, Phillips DI, Giannella-Neto A, Simpson DM. Heartrate and blood-pressure variability during psychophysiological tasks involving speech: influence of respiration. Psychophysiology 2007;44: 767-78. 


\section{Funding and Conflicts of Interest Disclosure}

The ESTER study was supported by grants from the Academy of Finland (SALVE program for 2009-2012 and grants $127437,129306,130326,134791$, and 263924 [to E.K.]); the Doctoral Program for Public Health, University of Tampere (to M.S.); the Emil Aaltonen Foundation (to E.K.); the Academy of Finland grant 267435 (to A.K.); the European Commission (Framework 5 award QLG1-CT-2000-001643 and Horizon2020 award 633595 DynaHealth [to M-R,J.]; Horizon2020 award 733280 RECAP Research on Children and
Adults Born Preterm [to E.K.]); the Finnish Foundation for Pediatric Research (to E.K.); the Finnish Government Special Subsidiary for Health Sciences (evo) (to J.E.); Finska Läkaresällskapet (to J.E.); the Jalmari and Rauha Ahokas Foundation (to E.K.); the Juho Vainio Foundation (to E.K., M.T., and M.V.); the National Graduate School of Clinical Investigation (to M.T.); the Novo Nordisk Foundation (to E.K. and M.V.); the Signe and Ane Gyllenberg Foundation (to J.E. and E.K.); the Sigrid Jusélius Foundation (to E.K.); and the Yrjö Jahnsson Foundation (to E.K., M.S., and M.V.). The authors declare no conflicts of interest. 


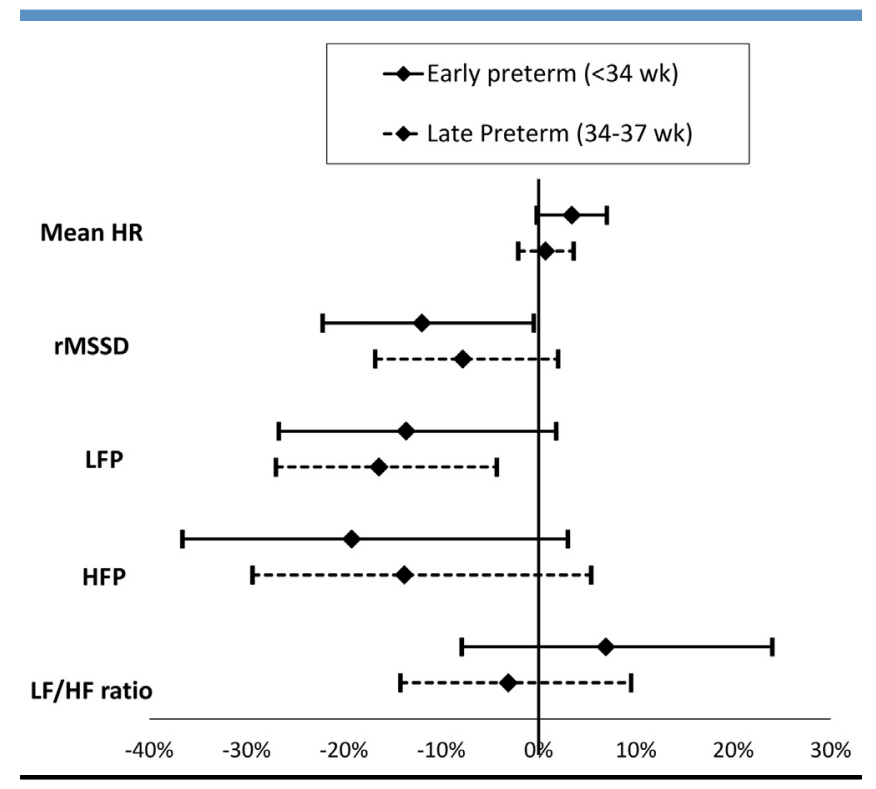

Figure 2. Mean percent difference in HRV measurements between early and later preterm young adults compared with controls born at term, with $95 \% \mathrm{Cls}$. The presented results are adjusted for age, sex, cohort of recruitment, and season of clinical examination. 
Table III. Mean differences ( $95 \%$ CIs) in autonomic control measurements between adults born early preterm and late preterm compared with controls by sex

\begin{tabular}{|c|c|c|c|c|}
\hline & & & Early preterm & Late preterm \\
\hline Measurements & Sex & Model & Mean difference (95\% Cl) & Mean difference (95\% Cl) \\
\hline \multirow[t]{3}{*}{ Mean HR (Control mean: 71.4 bpm) } & Women & 1 & $2.9(-1.9$ to 7.9$)$ & -0.2 (-4.0 to 3.8$)$ \\
\hline & & 2 & $0.9(-4.4$ to 6.5$)$ & -0.8 ( -4.7 to 3.3$)$ \\
\hline & & 3 & $-0.8(-6.1$ to 4.7$)$ & $-2.1(-6.0$ to 2.1$)$ \\
\hline \multirow{3}{*}{ Mean HR (Control mean: 67.1 bpm) } & Men & 1 & $3.8(-1.4$ to 9.2$)$ & $1.8(-2.5$ to 6.2$)$ \\
\hline & & 2 & $2.3(-3.0$ to 8.0$)$ & $1.1(-3.4$ to 5.8$)$ \\
\hline & & 3 & $1.6(-4.0$ to 7.4$)$ & $0.7(-3.9$ to 5.6$)$ \\
\hline \multirow[t]{3}{*}{ rMSSD (Control mean: $53.8 \mathrm{~ms}$ ) } & Women & 1 & $-11.4(-25.9$ to 5.9$)$ & $-6.8(-19.4$ to 7.9$)$ \\
\hline & & 2 & $-7.8(-24.5$ to 12.6$)$ & $-6.0(-19.1$ to 9.2$)$ \\
\hline & & 3 & $-1.5(-19.4$ to 20.5$)$ & $0.1(-14.0$ to 16.4$)$ \\
\hline \multirow{3}{*}{ rMSSD (Control mean: $55.6 \mathrm{~ms}$ ) } & Men & 1 & -12.7 ( -26.6 to 3.9$)$ & -9.6 (-21.8 to 4.6$)$ \\
\hline & & 2 & $-12.7(-27.5$ to 5.1$)$ & -10.8 ( -23.6 to 4.3$)$ \\
\hline & & 3 & $-9.8(-25.6$ to 9.4$)$ & $-8.6(-22.3$ to 7.5$)$ \\
\hline \multirow[t]{3}{*}{ LFP (Control mean: $1584.7 \mathrm{~ms}^{2}$ ) } & Women & 1 & $-11.4(-30.1$ to 12.3$)$ & $-12.8(-28.1$ to 5.8$)$ \\
\hline & & 2 & -7.5 ( -29.4 to 21.2$)$ & $-10.7(-27.2$ to 9.5$)$ \\
\hline & & 3 & $0.2(-23.8$ to 31.9$)$ & $-5.2(-22.9$ to 16.6$)$ \\
\hline \multirow[t]{3}{*}{ LFP (Control mean: $2017.9 \mathrm{~ms}^{2}$ ) } & Men & 1 & $-15.7(-33.0$ to 6.0$)$ & $-19.8(-33.8$ to -2.8$)$ \\
\hline & & 2 & $-19.6(-37.1$ to 2.6$)$ & $-22.7(-37.0$ to -5.1$)$ \\
\hline & & 3 & $-17.2(-35.8$ to 6.8$)$ & $-21.5(-36.7$ to -2.7$)$ \\
\hline \multirow[t]{3}{*}{ HFP (Control mean: $1016.7 \mathrm{~ms}^{2}$ ) } & Women & 1 & $-20.4(-43.7$ to 12.5$)$ & $-8.2(-30.8$ to 21.9$)$ \\
\hline & & 2 & $-15.5(-42.7$ to 24.7$)$ & $-7.6(-31.1$ to 23.9$)$ \\
\hline & & 3 & $-4.6(-35.4$ to 41.1$)$ & $5.2(-21.7$ to 41.2$)$ \\
\hline \multirow[t]{3}{*}{ HFP (Control mean: $1049.4 \mathrm{~ms}^{2}$ ) } & Men & 1 & $-18.5(-42.3$ to 15.1$)$ & $-20.2(-40.2$ to 6.6$)$ \\
\hline & & 2 & $-20.9(-45.3$ to 14.3$)$ & $-24.1(-44.3$ to 3.5$)$ \\
\hline & & 3 & $-14.7(-41.9$ to 25.1$)$ & $-20.2(-42.3$ to 10.2$)$ \\
\hline \multirow{3}{*}{ LF/HF (Control mean 1.6) } & Women & 1 & $11.4(-9.2$ to 36.6$)$ & $-5.0(-19.6$ to 12.2$)$ \\
\hline & & 2 & $9.4(-12.9$ to 37.5$)$ & $-3.4(-18.7$ to 14.8$)$ \\
\hline & & 3 & $5.0(-16.8$ to 32.5$)$ & $-9.9(-24.4$ to 7.4$)$ \\
\hline \multirow{3}{*}{ LF/HF (Control mean 1.9) } & Men & 1 & 3.5 (-16.8 to 28.6$)$ & 0.5 (-16.2 to 20.5$)$ \\
\hline & & 2 & $1.6(-19.3$ to 28.0$)$ & $1.8(-16.1$ to 23.6$)$ \\
\hline & & 3 & -2.9 (-23.5 Тo 23.1) & $-1.7(-19.5$ to 20.2$)$ \\
\hline
\end{tabular}

Model 1 (Women: $n=303$, Men: $n=297)$ : Age, sex, cohort of recruitment, and season of clinical examination.

Model 2 (Women: $n=303$, Men: $n=297$ ): Model 1 plus birth weight SD score, gestational diabetes mellitus, gestational hypertension, maternal preeclampsia, parental education, and parental smoking.

Model 3 (Women: $n=294$, Men: $n=289$ ): Model 2 plus smoking, BMl, height, and physical activity.

All group means are geometric means. Mean differences have been calculated from log transformed values, back-transformed, and expressed as percentage difference. 
Table IV. Mean differences $(95 \% \mathrm{CIs})$ in autonomic control measurements between very low birth weight adults compared with controls

\begin{tabular}{|c|c|c|c|}
\hline \multirow[b]{2}{*}{ Measurements } & \multirow[b]{2}{*}{ Model } & \multicolumn{2}{|c|}{ VLBW $(<1500 \mathrm{~g}) \mathrm{n}=28$} \\
\hline & & $\begin{array}{c}\text { Mean } \\
\text { difference } \\
(95 \% \mathrm{Cl})\end{array}$ & $\begin{array}{c}P \\
\text { value }\end{array}$ \\
\hline \multirow[t]{3}{*}{ Mean HR (Control mean: 69.2 bpm) } & 1 & $6.7(-0.1$ to 13.9$)$ & .05 \\
\hline & 2 & $3.6(-4.0$ to 11.8$)$ & .36 \\
\hline & 3 & $1.4(-6.2$ to 9.7$)$ & .72 \\
\hline \multirow[t]{3}{*}{ rMSSD (Control mean: $54.7 \mathrm{~ms}$ ) } & 1 & -18.1 ( -35.6 to 4.1$)$ & .10 \\
\hline & 2 & $-15.8(-36.2$ to 11.2$)$ & .22 \\
\hline & 3 & $-12.7(-34.6$ to 16.4$)$ & .35 \\
\hline \multirow[t]{3}{*}{ LFP (Control mean: $1788.2 \mathrm{~ms}^{2}$ ) } & 1 & $-25.7(-45.3$ to 0.9$)$ & .06 \\
\hline & 2 & $-26.5(-48.4$ to 4.5$)$ & .09 \\
\hline & 3 & -21.6 ( -45.8 to 13.3$)$ & .19 \\
\hline \multirow[t]{3}{*}{ HFP (Control mean: $1032.9 \mathrm{~ms}^{2}$ ) } & 1 & $-28.5(-55.4$ to 14.6$)$ & .16 \\
\hline & 2 & $-31.1(-60.1$ to 19.0$)$ & .18 \\
\hline & 3 & -26.7 ( -58.4 to 29.2$)$ & .28 \\
\hline \multirow[t]{3}{*}{ LF/HF (Control mean 1.7) } & 1 & $3.9(-21.7$ to 37.8$)$ & .79 \\
\hline & 2 & 6.6 ( -23.4 to 48.2$)$ & .70 \\
\hline & 3 & $6.9(-24.2$ to 50.8$)$ & .70 \\
\hline
\end{tabular}

Model $1(n=304)$ : Age, sex, cohort of recruitment, and season of clinical examination.

Model $2(n=304)$ : Model 1 plus birth weight SD score, gestational diabetes mellitus, gesta-

tional hypertension, maternal preeclampsia, parental education, and parental smoking.

Model $3(n=295)$ : Model 2 plus smoking, BMI, height, and physical activity.

All group means are geometric means. Mean differences have been calculated from log trans-

formed values, back-transformed, and expressed as percentage difference.

Table VI. Correlations between HRV measurements and office blood pressure

\begin{tabular}{lcccc}
\hline Measurements & $\begin{array}{c}\text { Systolic blood } \\
\text { pressure, mean of } \\
\text { 3 measurements }\end{array}$ & $\begin{array}{c}\boldsymbol{P} \\
\text { value }\end{array}$ & $\begin{array}{c}\text { Diastolic blood } \\
\text { pressure, mean of } \\
\text { 3 measurements }\end{array}$ & $\begin{array}{c}\boldsymbol{P} \\
\text { value }\end{array}$ \\
\hline Mean HR & 0.161 & $<.001$ & 0.289 & $<.001$ \\
rMSSD & -0.144 & $<.001$ & -0.252 & $<.001$ \\
LFP & -0.146 & $<.001$ & -0.245 & $<.001$ \\
HFP & -0.127 & .002 & -0.232 & $<.001$ \\
LF/HF & 0.046 & .26 & 0.108 & .008 \\
\hline
\end{tabular}

The correlations have been calculated from log-transformed HRV measurements. 